\title{
COVID-19 and Black, Asian, and Minority Ethnic Communities: A Complex Relationship Without Just Cause
}

Peter Phiri ${ }^{1,2}$, DipHE, BSc, PhD; Gayathri Delanerolle ${ }^{3}$, BSc, MBBCHIR, MSc; Ayaat Al-Sudani ${ }^{1}$, MSc; Shanaya Rathod $^{1}$, MSc, MRCPsych, MD

\footnotetext{
${ }^{1}$ Research \& Development Department, Tom Rudd Unit, Moorgreen Hospital, Southern Health NHS Foundation Trust, Southampton, United Kingdom

${ }^{2}$ University of Southampton, Primary Care, Population Sciences and Medical Education, Faculty of Medicine, Aldermoor Health Centre, Southampton, United Kingdom
}

${ }^{3}$ Oxford Brain Health Clinical Trials Unit, Department of Psychiatry, Warnford Hospital, University of Oxford, Oxford, United Kingdom

\author{
Corresponding Author: \\ Peter Phiri, DipHE, BSc, PhD \\ Research \& Development Department \\ Tom Rudd Unit, Moorgreen Hospital \\ Southern Health NHS Foundation Trust \\ Research \& Development Dept. \\ Clinical Trials Facility, Tom Rudd Unit, \\ Southampton, SO30 3JB \\ United Kingdom \\ Phone: 4402380475112 \\ Email: peter.phiri@southernhealth.nhs.uk
}

\section{Abstract}

Emerging evidence has indicated a negative and disproportionate impact of COVID-19 on Black, Asian, and minority ethnic (BAME) communities. Previous studies have already reported that biological and social risk factors increase disease susceptibility, particularly in BAME communities. Despite frontline workers in ethnic minority communities in the United Kingdom's National Health Service attempting to quell the pandemic, disproportionate numbers of BAME physicians and other health care workers have died of COVID-19. This unprecedented situation highlights ethical and moral implications, which could further augment the impact of the pandemic on their mental health. While the government attempts to mitigate the rate of virus transmission, certain key factors inadvertently augment the negative impact of the pandemic on the mental health and general well-being of BAME communities. This study examined the available literature to explore the association between, and the wider impact of, COVID-19 on BAME communities. Furthermore, this study aims to raise awareness and provide a deeper insight into current scientific discussions.

(JMIR Public Health Surveill 2021;7(2):e22581) doi: 10.2196/22581

\section{KEYWORDS}

BAME; COVID-19; ethnicity; health care professionals; health care worker; impact; inequalities; minority; risk

\section{The Disproportionate Impact of COVID-19 on Black, Asian, and Minority Ethnic Communities}

The first 10 health care professionals in the United Kingdom to die of COVID-19 were from the Black, Asian, and minority ethnic (BAME) communities. This raised concerns of a potential association between ethnicity and a disproportionate impact of COVID-19 on these communities [1-3]. The Intensive Care National Audit and Research Centre published UK data sets from April 10, 2020, showing that one-third of COVID-19 patients admitted to critical care units belonged to an ethnic minority group. Among 3883 COVID-19 patients, $14 \%(\mathrm{n}=486)$ were Asian and 12\% ( $\mathrm{n}=402)$ were Black [4]. Similarly, The Guardian [5] reported that among 12,593 patients, 19\% $(n=2393)$ of those who died of COVID-19 in hospital up till April 10, 2020, were from BAME communities. These data are discordant to those of BAME individuals in the general population in the United Kingdom (14\%) [1,6]. In addition, The Washington Post [1] reported that in the United States, Black-majority counties have 3-fold the number COVID-19 cases and almost 6-fold the number of COVID-19-related deaths compared to White-majority counties. However, caution should 
be exercised when generalizing across different health care systems [1]. A Public Health England (PHE) report [7] acknowledges the disproportionate impact of COVID-19 on BAME communities, reporting increased mortality, despite the absence of measures to potentially address the concerns identified therein.

\section{Deaths Among National Health Service Health Care Professionals in BAME Communities}

On March 12, 2020, chief medical officers in the United Kingdom elevated the country's risk status from moderate to high, and on March 23, 2020, the prime minister imposed a nationwide lockdown [8]. Since then, 181 National Health Service (NHS) workers have died of COVID-19 [9]. This figure, however, mainly relies on reports from hospitals within England only. Numerous reports have claimed that approximately $62 \%-75 \%$ of COVID-19-related deaths among health care workers occurred in BAME workers [1,2,4]. This is alarming because only one-third of NHS physicians in hospitals or community services in England belong to Asian (27.2\%) or Black $(6.95 \%)$ communities [10].

\section{Disease Susceptibility and Predictability in BAME Communities}

Many experts, including Duncan Young (professor, Intensive Care Medicine, University of Oxford), Dr Riyaz Patel (associate professor, Cardiology, University College London), and Naveed Sattar (professor, Metabolic Medicine, University of Glasgow), have suggested that ethnic minorities are at an increased risk of SARS-CoV-2 infection, severe disease, and poor outcomes owing to socially and biologically relevant reasons [11]. First, ethnicity could play a major role in disease transmission owing to cultural, behavioral, and societal differences including those in health-seeking behaviors [12], cohabiting lifestyle [13], and lower socioeconomic status. The disease transmission risk is further increased among NHS workers. Furthermore, individuals in ethnic minority communities are disproportionally employed in fields including those associated with public transport or delivery services, where there is a known, markedly higher risk of virus transmission. It is also common for BAME households to have several generations cohabiting within close confinement as culture and family are potentially important aspects of identity in these communities. Thus, it could be challenging for BAME communities to follow social distancing protocols [14,15]. Furthermore, complexities in other comorbidities such as diabetes, hypertension, and cardiovascular diseases are commonly associated with South Asians [11]. Another theory is based on the similarities observed between the risk of morality during the last major influenza crisis - the H1N1 epidemic - and ethnic minority communities in 2009-2010 and during the first postpandemic season of 2010-2011 in England. From this data set, 67 of 337 (19.9\%) individuals were from BAME communities. Furthermore, ethnic minorities have been at a higher mortality risk than the Caucasian population during the
2009-2010 pandemic, with individuals of Pakistani descent being at the highest risk [16].

In addition, early studies on the disproportionate prevalence and severity of respiratory diseases among BAME communities suggest predictable health outcomes based on socioeconomic status [17]. Social stressors and environmental adversity appear to be linked to an elevated risk of cardiovascular disease and other comorbidities [16]. According to Carol Cooper, the head of equality, diversity and human rights at Birmingham Community Healthcare NHS Trust [18]:
Many of us knew that BAME people would be overrepresented - given their proportion of the population - in the mortality and morbidity figures because of the comorbidities that exist in our communities, because of the location of our communities in terms of the workforce being on the frontline [and] because of the amount of people that are caught in the poverty trap and live in households that have higher occupancy.

Despite previous warnings and the need for public health authorities to identify at-risk populations, a literature review indicated that only 2 of $29(7 \%)$ publications reported disaggregated data on ethnicity (case series without ethnicity-specific outcomes) [13]. The countries that initially reported the highest number of COVID-19 cases did not report data on ethnicity [13]. Researchers in the United Kingdom did not acquire or publish information on ethnicity until concerns of an association between COVID-19 and ethnicity began to emerge $[3,13,19]$. As is the case in many diseases, researchers and policy makers do not often consider ethnicity as a core factor until deaths among BAME communities become prominent in mortality data or media reports.

In addition to reports from the United Kingdom [11], those from the United States have indicated that chronic conditions such as diabetes, asthma, hypertension, kidney disease, and obesity are more common in Black American than in White American populations [20]. These conditions are associated with poor outcomes in COVID-19 cases. Moreover, Kirby [20] reported:

The risks of COVID-19 to Indigenous communities
could not be clearer. More than 1 in 3 Indigenous
Australian adults report having either cardiovascular
disease, diabetes, or renal disease, and onset of these
diseases often occurs 20 years earlier than the
non-Indigenous population.

The NHS Long Term Plan has identified and prioritized more common conditions including diabetes, hypertension, and obesity, but has overlooked other, more specific health conditions that increase disease severity in BAME communities, such as asthma and kidney and cardiovascular diseases [21,22]. Similarly, these conditions do not seem to be prioritized by US health care authorities [23]. 


\section{Inequalities and Their Psychological Impact}

Stress-related physiological and general psychological responses, such as recurrent experiences of discrimination, can significantly impact health by increasing the risk of heart disease, diabetes, and infections [24]. The PHE report of 2020 [22] asserts that this pandemic did not generate health inequalities but merely exposed and exacerbated the longstanding health and socioeconomic inequalities affecting BAME communities in the United Kingdom. Although this statement might hold true, perceptions of the underlying causal relationships vary greatly and are difficult to unravel [7] Compared to the United Kingdom, hate crimes against Asian Americans have increased in the United States [25]. A study from the Healthforce Center at the University of California San Francisco [25] reported that $25 \%$ of working nurses are either Asian-born or Asian American in California alone. In the United Kingdom, over 1 in 5 allied health professionals, such as nurses, health visitors, and midwives, belong to a BAME community [26]. Similarly, Cook et al [27] reported that among 119 NHS deaths recorded in the NHS staff, 35 occurred among nurses, 27 among health care workers, and 18 among physicians. Furthermore, nurses belonging to BAME communities are more likely to report higher levels of stress and show signs of posttraumatic stress or other common mental health disorders than their non-BAME counterparts [28]. Furthermore, social media platforms reporting these stories can potentially influence global communities [29].

In an interview with Nursing Times, Carol Cooper added, "BME staff feel that they are being put on Covid wards and exposed to patients with Covid over and above their colleagues" [18]. The NHS Staff Survey of 2020 and data from the NHS Workforce Race Equality Standard (WRES) consistently provide evidence on staff in BAME communities, reporting instances of discrimination, harassment, and victimization from other staff members and the general public [26]. Consequently, some NHS staff from BAME communities may not feel confident in requesting necessary items such as personal protective equipment (PPE) and COVID-19 tests to ensure their safety. Feedback from BAME staff [14] also suggested that some forms of PPE may not be suitable. For example, some Muslim health care professionals wear a head covering (referred to as a "hijab"); hence, wearing face masks and visors may be difficult. In addition, some Muslim and Sikh men may have a beard, which could also affect the fit of face masks or PPE. Furthermore, key measures or restrictions to prevent the spread of infection could potentially be more hazardous to ethnic minorities than to others, such as withdrawing key services, implementing no-visitor policies, and social isolation or quarantine [14]. Without translation or language support, some patients are unable to articulate their health needs. Isolation is difficult owing to the multigenerational households in these communities. Furthermore, the closure of religious or community centers can impact psychological well-being. Compared to nonattenders, individuals from BAME communities who visit religious places of worship or community centers presented reduced suicide rates [30]. Closure of churches, community centers, and mosques can therefore result in poor mental health; this can, in turn, affect physical health, thus reducing the chances of survival among individuals of BAME communities [24,31].

In addition, Greenberg et al [32] reported that health care professionals are at an increased risk of "moral injury" and mental health difficulties. Health care workers are faced with detrimental decision making and extreme pressures both before and during the pandemic. Health care workers must be able to ensure the welfare of both themselves and others. They must maintain a balance between "desire" and "duty," while working with insufficient resources, particularly during COVID-19 [32]. Furthermore, Greenberg et al [32] reported that individuals developing moral injuries were likely to have negative thoughts about themselves or others as well as feelings of shame, guilt, or disgust. Negative thoughts can often lead to the development of common mental health problems, including depression and posttraumatic stress disorder, in turn affecting physiological health and even leading to suicidal ideation.

Health workers in Pakistan who have been under physical and psychological pressure have seen an increased incidence of mental health symptoms, such as heightened fears and anxiety, which could have long-term and detrimental effects on overall well-being [28]. Rana et al [28] suggested that intervention might involve the development and delivery of online content by mental health professionals to spread awareness of the psychological impact of pandemics. Psychological factors such as fear and prejudices associated with COVID-19 have led to notable levels of xenophobia, and this might have led to Zahidul Islam-a 36-year-old Bangladeshi man-committing suicide on March 25, 2020 [33,34]. This again may support the negative effects of closing religious and community centers or other places of importance, and social isolation. Zahidul may have also believed it was his "moral duty" not to transmit the virus, although his tests revealed that he did not harbor the infection [34].

Accordingly, researchers from National University Health System and Yong Loo Lin School of Medicine used a self-administered questionnaire to examine psychological distress, depression, and anxiety among health care workers in Singapore [35]. Tan et al [35] reported that during the peak of the pandemic, the incidence of anxiety was increased among nonmedical health care workers, probably owing to "less first-hand medical information on the outbreak and less intensive training on PPE and infection control measures." These suggestions are consistent with those of a systematic literature review [36] wherein numerous studies highlighted the importance of preparation, including training and work experience, during a crisis. Brooks et al [37] aimed to identify the social and occupational factors affecting the psychological well-being of health care workers involved in the severe acute respiratory syndrome crisis. They reported that "those who perceived their training as inadequate were more likely to experience burnout, posttraumatic stress and longer continuing perceived risk" [37]. This may be why death rates among NHS workers in BAME communities have been so high, and the WRES [26] similarly indicated that White NHS workers are more likely to have greater access to nonmandatory training 
and continuous professional development than their BAME counterparts. Thus, White people may be better informed and therefore better able to cope with pandemics than their BAME counterparts.

The COVID-19 pandemic has threatened the health and lives of millions of individuals worldwide, and data from the Johns Hopkins University have reported 38,272,349 confirmed cases and 1,088,051 global deaths as of June 30, 2020 [38]. As of October 2, 2020, the United Kingdom has reported 42,369 deaths [39]. Figures 1 and 2 show the total deaths at NHS hospitals in England. As such, a virus may not discriminate among individuals; however, society apparently does, as emphasized in a recent editorial [40].

Negative effects of government measures to mitigate virus transmission albeit unintentionally increase health inequalities, including mental health inequalities [14,24,30,31]. Inequalities in wages and career development in the NHS, combined with discrimination at work and in society, restrict BAME workers to certain roles potentially rendering their specialties and services critical for combatting COVID-19 and other pandemics
[40]. As previously indicated, health care workers in BAME communities may not have the confidence to voice their concerns regarding inadequate PPE, long hours of work, and low wages, which unnecessarily places them at a higher risk of succumbing to the infection [40]. Even at higher-level positions, BAME physicians and health care workers are perhaps as vulnerable as those at lower socioeconomic positions [40]. Stress, inequality, trauma, discrimination, and marginalization can negatively impact the working environment of individuals belonging to BAME communities. Furthermore, inadequacies apparent within the research sphere fail to address the inequalities among BAME groups. This was observed even during past epidemics such as the H1N1 influenza (2009), polio (2014), Ebola in West Africa (2014), Zika (2016), and Ebola in the Democratic Republic of the Congo (2019) [27], and notable effects were also observed among individuals in BAME communities in the United Kingdom [16]. Inequalities in addressing biological or physiological risk factors will inevitably lead to poor outcomes among ethnic minorities than among other populations $[11,40]$. 
Figure 1. Total COVID-19-related deaths at National Health Service Hospitals in England (data up to June 19, 2020).

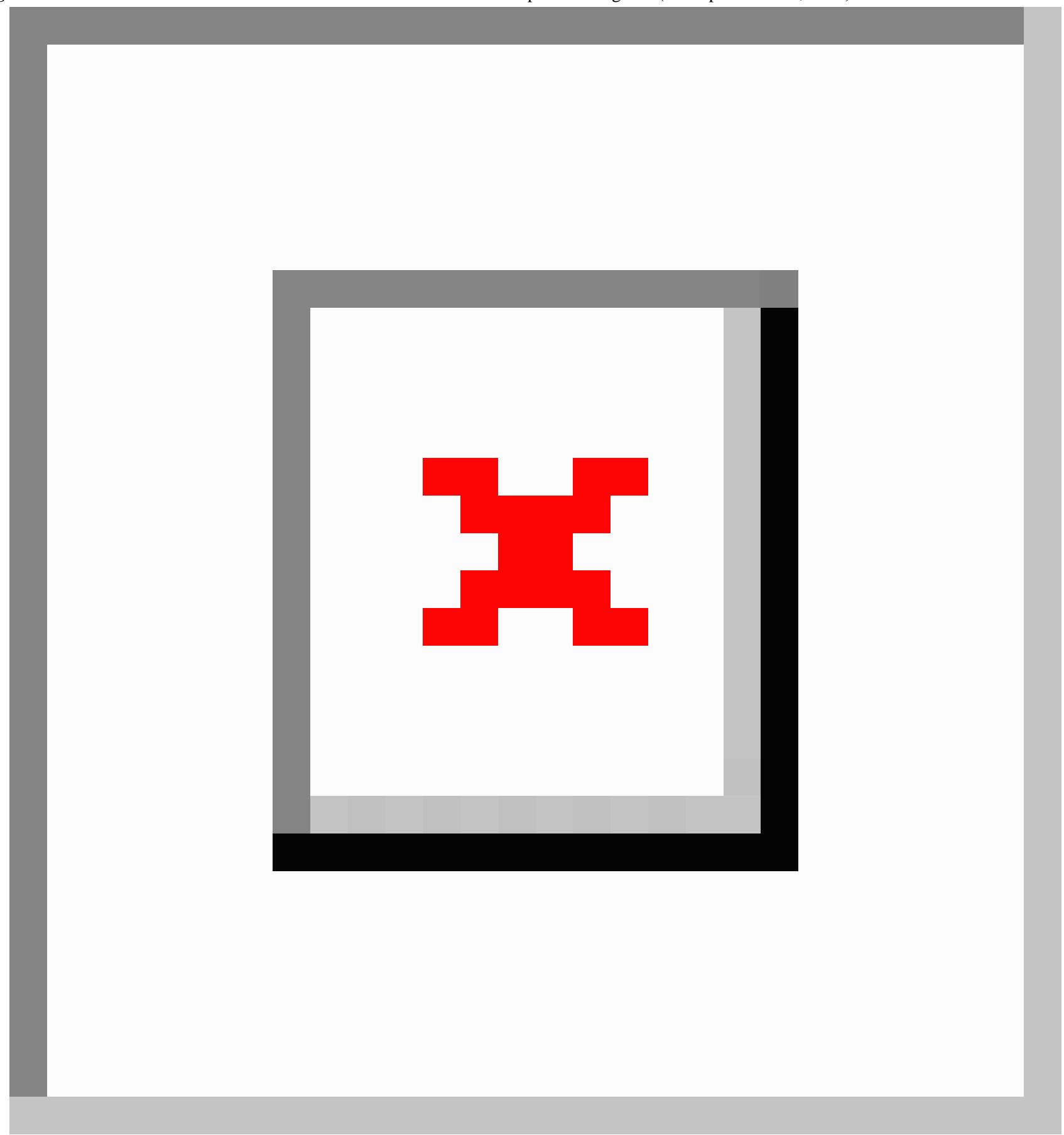


Figure 2. COVID-19-related deaths by age in England (data up to June 19, 2020).

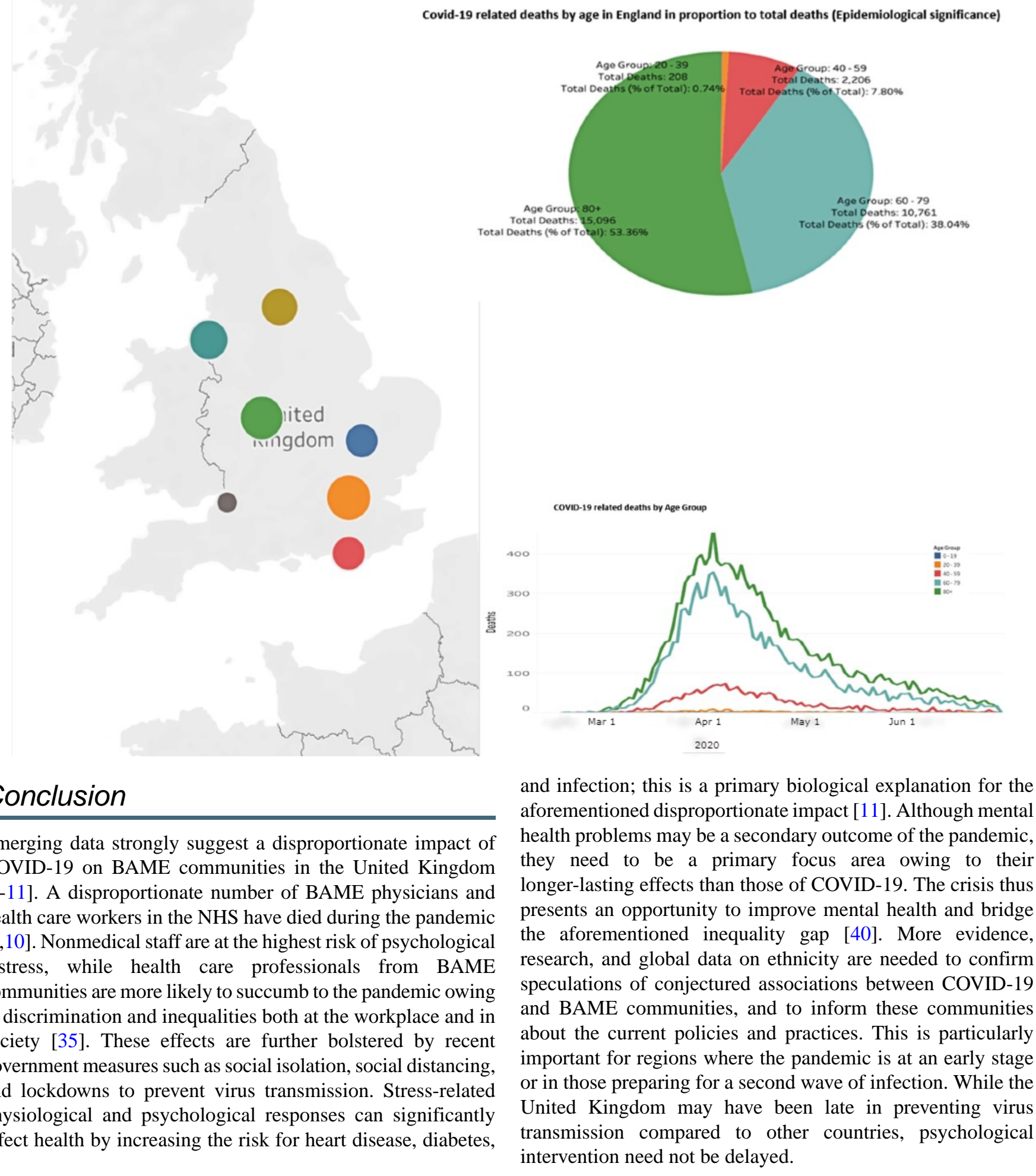

\section{Authors' Contributions}

PP conceived the study. PP and AAS wrote the first draft of the manuscript. PP, AAS, GD, and SR revised the manuscript critically for important intellectual content. All authors read and approved the final version of the manuscript.

\section{Conflicts of Interest}

PP received grants from NovoNordisk, Queen Mary University of London, and John Wiley \& Sons during the conduct of the study.

\section{References}


1. Khunti K, Singh AK, Pareek M, Hanif W. Is ethnicity linked to incidence or outcomes of covid-19? BMJ 2020 Apr 20;369(4):m1548-m1394 [FREE Full text] [doi: 10.1136/bmj.m1548] [Medline: $\underline{\text { 32312785] }}$

2. Nagpaul C. The disproportionate impact of covid-19 on ethnic minority healthcare workers. The BMJ Opinion. 2020 Apr 20. URL: https://blogs.bmj.com/bmj/2020/04/20/

chaand-nagpaul-the-disproportionate-impact-of-covid-19-on-ethnic-minority-healthcare-workers/ [accessed 2020-04-28]

3. Siddique H. UK government urged to investigate coronavirus deaths of BAME doctors. The Guardian. 2020 Apr 10. URL: https://www.theguardian.com/society/2020/apr/10/uk-coronavirus-deaths-bame-doctors-bma [accessed 2020-04-28]

4. ICNARC report on COVID-19 in critical care: 10 April 2020. Intensive Care National Audit \& Research Centre. URL: https://www.icnarc.org/Our-Audit/Audits/Cmp/Reports [accessed 2020-04-29]

5. Barr C, Kommenda N, McIntyre N, Voce A. Ethnic minorities dying of Covid-19 at higher rate, analysis shows. The Guardian. 2020 Apr 22. URL: https://www.theguardian.com/world/2020/apr/22/ racial-inequality-in-britain-found-a-risk-factor-for-covid-19 [accessed 2020-04-29]

6. 2011 Census. Office for National Statistics. 2011. URL: https://www.ons.gov.uk/census/2011census [accessed 2020-04-29]

7. Disparities in the risk and outcomes of COVID-19. Public Health England. 2020 Aug. URL: https://tinyurl.com/y54koq41 [accessed 2020-04-29]

8. Prime Minister's statement on coronavirus (COVID-19): 23 March 2020. Government of the United Kingdom. 2020 Mar 23. URL: https://www.gov.uk/government/speeches/pm-address-to-the-nation-on-coronavirus-23-march-2020 [accessed 2020-02-10]

9. Allen-Kinross P. We don't know exactly how many NHS workers have died from Covid-19. Full Fact. 2020 May 22. URL: https://fullfact.org/health/we-dont-know-exactly-how-many-nhs-workers-have-died-covid-19/ [accessed 2020-06-01]

10. NHS Workforce Statistics - March 2019 (Including supplementary analysis on pay by ethnicity). NHS Workforce Statistics. 2019 Jul 27. URL: https://digital.nhs.uk/data-and-information/publications/statistical/nhs-workforce-statistics/ nhs-workforce-statistics---march-2019-provisional-statistics [accessed 2020-06-01]

11. Expert comments on BME groups and risk of hospitalisation with COVID-19. Science Media Centre. 2020 Apr 09. URL: https://www.sciencemediacentre.org/expert-comments-on-bme-groups-and-risk-of-hospitalisation-with-covid-19/ [accessed 2020-04-29]

12. Rathod S, Kingdon D, Phiri P, Gobbi M. Developing culturally sensitive cognitive behaviour therapy for psychosis for ethnic minority patients by exploration and incorporation of service users' and health professionals' views and opinions. Behav Cogn Psychother 2010 Oct;38(5):511-533. [doi: 10.1017/S1352465810000378] [Medline: 20630118]

13. Pareek M, Bangash MN, Pareek N, Pan D, Sze S, Minhas JS, et al. Ethnicity and COVID-19: an urgent public health research priority. Lancet 2020 May 02;395(10234):1421-1422 [FREE Full text] [doi: 10.1016/S0140-6736(20)30922-3] [Medline: $\underline{32330427]}$

14. The impact of COVID-19 on BME communities and health and care staff. NHS Confederation. 2020 Apr. URL: https:/ /tinyurl.com/yd5p2r31 [accessed 2020-04-30]

15. Catney G, Sabater A. Ethnic minority disadvantage in the labour market. Joseph Rowntree Foundation. 2015 Mar 30. URL: https://www.jrf.org.uk/report/ethnic-minority-disadvantage-labour-market [accessed 2020-04-30]

16. Zhao H, Harris RJ, Ellis J, Pebody RG. Ethnicity, deprivation and mortality due to 2009 pandemic influenza A(H1N1) in England during the 2009/2010 pandemic and the first post-pandemic season. Epidemiol Infect 2015 Dec;143(16):3375-3383. [doi: 10.1017/S0950268815000576] [Medline: 25850904]

17. Myers EM. Compounding Health Risks and Increased Vulnerability to SARS-CoV-2 for Racial and Ethnic Minorities and Low Socioeconomic Status Individuals in the United States. Preprints. Preprint posted online on April 15, 2020 [FREE Full text] [doi: 10.1080/17437199.2015.1138093]

18. Ford M. Exclusive: BME nurses 'feel targeted' to work on Covid-19 wards. Nursing Times. 2020 Apr 17. URL: https:/ /www.nursingtimes.net/news/coronavirus/exclusive-bme-nurses-feel-targeted-to-work-on-covid-19-wards-17-04-2020/ [accessed 2020-04-29]

19. Croxford R. Coronavirus cases to be tracked by ethnicity. BBC News. 2020 Apr 18. URL: https://www.bbc.co.uk/news/ health-52338101 [accessed 2020-04-29]

20. Kirby T. Evidence mounts on the disproportionate effect of COVID-19 on ethnic minorities. Lancet Respir Med 2020 Jun;8(6):547-548 [FREE Full text] [doi: 10.1016/S2213-2600(20)30228-9] [Medline: 32401711]

21. NHS Long Term Plan. NHS. URL: https://www.longtermplan.nhs.uk/ [accessed 2020-10-01]

22. Beyond the data: Understanding the impact of COVID-19 on BAME groups. Public Health England. 2020 Jun. URL: https:/ /tinyurl.com/y797mv8c [accessed 2021-01-26]

23. National Health Initiatives, Strategies and Action Plans. Centers for Disease Control and Prevention. URL: https://www. cdc.gov/publichealthgateway/strategy/index.html [accessed 2020-10-01]

24. Anderson KF. Diagnosing Discrimination: Stress from Perceived Racism and the Mental and Physical Health Effects*. Sociol Inq 2012 Sep 07;83(1):55-81 [FREE Full text] [doi: 10.1111/j.1475-682X.2012.00433.x]

25. Natividad I. Racist harassment of Asian health care workers won't cure coronavirus. Berkeley News. 2020 Apr 09. URL: https://news.berkeley.edu/2020/04/09/racist-harassment-of-asian-health-care-workers-wont-cure-coronavirus/ [accessed 2020-05-01] 
26. The WRES implementation team. NHS Workforce Race Equality Standard. NHS. 2020 Feb. URL: https://www. england.nhs.uk/wp-content/uploads/2020/01/wres-2019-data-report.pdf [accessed 2020-05-04]

27. Cook T, Kursumovic E, Lennane S. Exclusive: deaths of NHS staff from covid-19 analysed. HSJ. 2020 Apr 22. URL: https://www.hsj.co.uk/exclusive-deaths-of-nhs-staff-from-covid-19-analysed/7027471.article [accessed 2020-04-29]

28. Rana W, Mukhtar S, Mukhtar S. Mental health of medical workers in Pakistan during the pandemic COVID-19 outbreak. Asian J Psychiatr 2020 Jun;51:102080 [FREE Full text] [doi: 10.1016/j.ajp.2020.102080] [Medline: 32283512]

29. Zarocostas J. How to fight an infodemic. Lancet 2020 Feb 29;395(10225):676 [FREE Full text] [doi: 10.1016/S0140-6736(20)30461-X] [Medline: 32113495]

30. VanderWeele TJ, Li S, Tsai AC, Kawachi I. Association Between Religious Service Attendance and Lower Suicide Rates Among US Women. JAMA Psychiatry 2016 Aug 01;73(8):845-851 [FREE Full text] [doi: 10.1001/jamapsychiatry.2016.1243] [Medline: 27367927]

31. Reger MA, Stanley IH, Joiner TE. Suicide Mortality and Coronavirus Disease 2019-A Perfect Storm? JAMA Psychiatry 2020 Apr 10. [doi: 10.1001/jamapsychiatry.2020.1060] [Medline: 32275300 ]

32. Greenberg N, Docherty M, Gnanapragasam S, Wessely S. Managing mental health challenges faced by healthcare workers during covid-19 pandemic. BMJ 2020 Mar 26;368:m1211. [doi: 10.1136/bmj.m1211] [Medline: 32217624]

33. Youth Suicide in Gaibandha Due to Doubt of Corona [Bangla]. Somoy News. 2020 Mar. URL: https://m.somoynews.tv/ pages/details/204558 [accessed 2020-04-30]

34. Mamun MA, Griffiths MD. First COVID-19 suicide case in Bangladesh due to fear of COVID-19 and xenophobia: Possible suicide prevention strategies. Asian J Psychiatr 2020 Jun;51:102073 [FREE Full text] [doi: 10.1016/j.ajp.2020.102073] [Medline: $\underline{32278889}$ ]

35. Tan BY, Chew NW, Lee GK, Jing M, Goh Y, Yeo LL, et al. Psychological Impact of the COVID-19 Pandemic on Health Care Workers in Singapore. Ann Intern Med 2020 Aug 18;173(4):317-320 [FREE Full text] [doi: 10.7326/M20-1083] [Medline: $\underline{32251513}$ ]

36. Iversen AC, Fear NT, Ehlers A, Hacker Hughes J, Hull L, Earnshaw M, et al. Risk factors for post-traumatic stress disorder among UK Armed Forces personnel. Psychol Med 2008 Apr;38(4):511-522 [FREE Full text] [doi: 10.1017/S0033291708002778] [Medline: 18226287 ]

37. Brooks SK, Dunn R, Amlôt R, Rubin GJ, Greenberg N. A Systematic, Thematic Review of Social and Occupational Factors Associated With Psychological Outcomes in Healthcare Employees During an Infectious Disease Outbreak. J Occup Environ Med 2018 Mar;60(3):248-257. [doi: 10.1097/JOM.0000000000001235] [Medline: 29252922]

38. COVID-19 Dashboard by the Center for Systems Science and Engineering (CSSE) at Johns Hopkins University. Coronavirus Resource Center: Johns Hopkins University. URL: https://coronavirus.jhu.edu/map.html [accessed 2020-06-30]

39. United Kingdom. Worldometer. URL: https://www.worldometers.info/coronavirus/country/uk/ [accessed 2020-10-02]

40. Kapilashrami A, Bhui K. Mental health and COVID-19: is the virus racist? Br J Psychiatry 2020 Aug;217(2):405-407 [FREE Full text] [doi: 10.1192/bjp.2020.93] [Medline: 32368995]

\author{
Abbreviations \\ BAME: Black, Asian, and minority ethnic \\ NHS: National Health Service \\ PHE: Public Health England \\ PPE: personal protective equipment \\ WRES: NHS Workforce Race Equality Standard
}

Edited by G Eysenbach; submitted 17.07.20; peer-reviewed by J Kaewkungwal, E Davies; comments to author 01.10.20; revised
version received 15.10.20; accepted 17.01.21; published 01.02.21
Please cite as:
Phiri P, Delanerolle G, Al-Sudani A, Rathod S
COVID-19 and Black, Asian, and Minority Ethnic Communities: A Complex Relationship Without Just Cause
JMIR Public Health Surveill 2021;7(2):e22581
URL: $\underline{\text { https://publichealth.jmir.org/2021/2/e22581 }}$
doi: $\underline{10.2196 / 22581}$
PMID: $\underline{33481752}$

CPeter Phiri, Gayathri Delanerolle, Ayaat Al-Sudani, Shanaya Rathod. Originally published in JMIR Public Health and Surveillance (http://publichealth.jmir.org), 01.02.2021. This is an open-access article distributed under the terms of the Creative Commons Attribution License (https://creativecommons.org/licenses/by/4.0/), which permits unrestricted use, distribution, and reproduction 
in any medium, provided the original work, first published in JMIR Public Health and Surveillance, is properly cited. The complete bibliographic information, a link to the original publication on http://publichealth.jmir.org, as well as this copyright and license information must be included. 